\title{
Avaliação da deposição de defensivos agrícolas sobre o aplicador e a influência de parâmetros meteorológicos
}

\author{
Evaluation of pesticide deposition on the applicator and the influence of meteorological parameters \\ Evaluación de la deposición de plaguicidas en el aplicador y la influencia de los parámetros
} meteorológicos

Priscila Souza Pereira

ORCID: https://orcid.org/0000-0001-5215-4851 Instituto Federal do Sudeste de Minas Gerais, Brasil E-mail: priscila.pereira@ifsudestemg.edu.br

Haroldo Carlos Fernandes

ORCID: https://orcid.org/0000-0001-5276-5441 Universidade Federal de Viçosa, Brasil

E-mail: haroldoufv@gmail.com

Paulo Roberto Cecon

ORCID: https://orcid.org/0000-0001-8213-0199 Universidade Federal de Viçosa, Brasil E-mail: cecon@ufv.br

Lucas Moraes Rufini de Souza

ORCID: https://orcid.org/0000-0003-4915-9795 Instituto Federal do Sudeste de Minas Gerais, Brasil E-mail: rufinilucas@gmail.com

Cleonice Campos Teixeira

ORCID: https://orcid.org/0000-0001-5823-3518 Universidade Federal de Viçosa, Brasil E-mail: cleonice.teixeira31@gmail.com

\begin{abstract}
Resumo
A utilização de defensivos agrícolas para proteção das lavouras é uma prática comum no agronegócio. No entanto, além de ser necessária a minimização dos impactos ambientais associados à esta prática, também é de suma importância que os trabalhadores estejam adequadamente protegidos, a fim de que não haja impactos à saúde ocupacional. Neste contexto, o presente artigo teve como objetivo avaliar a deposição de defensivos agrícolas sobre o aplicador durante o preparo e a aplicação da calda em condições padronizadas e em condições adversas de vento e vazamento. $\mathrm{O}$ experimento foi conduzido em casa de vegetação, avaliando-se a aplicação de dois defensivos agrícolas com pulverizador costal manual e ponta com formato do jato em cone cheio. Para a avaliação da deposição dos produtos sobre o aplicador foram utilizadas etiquetas de papel hidrossensível, sobre os EPIs, posicionadas em 28 partes do corpo. Os resultados demonstraram que todas as partes do corpo avaliadas foram atingidas por defensivos agrícolas. O vento também se mostrou um parâmetro meteorológico relevante para o aumento da deposição de defensivos sobre o aplicador, bem como os vazamentos acidentais de calda. Conclui-se que a aplicação de defensivos agrícolas por meio da utilização de pulverizador costal manual demanda a utilização de EPIs capazes de neutralizar a exposição à agentes químicos para todas as partes do corpo dos aplicadores, de forma a promover a adequada segurança ocupacional e que a incidência de vento também potencializa a deriva e consequente aumento da deposição de defensivos agrícolas sobre o aplicador.
\end{abstract}

Palavras-chave: Agrotóxico; Pulverização; Segurança Ocupacional.

\begin{abstract}
The use of pesticides to protect crops is a common practice in agribusiness. However, in addition to being necessary to minimize the environmental impacts associated with this practice, it is also of paramount importance that global workers be calculated so that there are no impacts on occupational health. In this context, this article aimed to evaluate the deposition of pesticides on the applicator during the preparation and application of the syrup under standardized conditions and in adverse conditions of wind and leakage. The experiment was carried out in a greenhouse, evaluating the application of two pesticides with a manual costal sprayer and a full cone-shaped jet tip. To assess the deposition of the products on the applicator, water-sensitive paper labels were used, on the PPE, positioned on 28 parts of the body. The results showed that all parts of the body evaluated were affected by pesticides. Wind is also a relevant meteorological parameter for increasing the deposition of pesticides on the applicator, as well as accidental grout leaks. It is concluded that the application of pesticides through the use of back spray requires the
\end{abstract}


use of PPE capable of neutralizing the exposure to chemical agents for all parts of the applicators' bodies, in order to promote adequate occupational safety and impact wind power also enhances drift and the consequent increase in the deposition of pesticides on the applicator.

Keywords: Pesticides; Pulverization; Occupational Safety.

\section{Resumen}

El uso de pesticidas para proteger los cultivos es una práctica común en la agroindustria. Sin embargo, además de ser necesario para minimizar los impactos ambientales asociados a esta práctica, también es de suma importancia que los trabajadores estén adecuadamente protegidos, para que no existan impactos en la salud ocupacional. En este contexto, este artículo tuvo como objetivo evaluar la deposición de plaguicidas en el aplicador durante la preparación y aplicación del jarabe en condiciones estandarizadas y en condiciones adversas de viento y fugas. El experimento se llevó a cabo en un invernadero, evaluando la aplicación de dos pesticidas con un aspersor costal manual y una punta de chorro completa en forma de cono. Para evaluar la deposición de los productos en el aplicador, se utilizaron etiquetas de papel sensibles al agua, en el EPI, colocadas en 28 partes del cuerpo. Los resultados mostraron que todas las partes del cuerpo evaluadas se vieron afectadas por los pesticidas. El viento también demostró ser un parámetro meteorológico relevante para aumentar la deposición de pesticidas en el aplicador, así como las fugas accidentales de lechada. Se concluye que la aplicación de plaguicidas mediante el uso de un espray manual de espalda requiere el uso de EPP capaces de neutralizar la exposición a agentes químicos en todas las partes del cuerpo de los aplicadores, con el fin de promover una adecuada seguridad ocupacional y que la incidencia del viento también mejora la deriva y el consiguiente aumento de la deposición de plaguicidas en el aplicador.

Palabras clave: Plaguicidas; Pulverización; Seguridad Ocupacional.

\section{Introdução}

A extensiva utilização de defensivos agrícolas tem trazido uma série de consequências, tanto para o ambiente como para a saúde do trabalhador, sendo considerado um problema de saúde pública nos países em desenvolvimento, especialmente aqueles com economias baseadas no agronegócio, como o Brasil (Araújo et al., 2007; Pereira \& Amorim, 2020; Peres, Oliveira-Silva, Della-Rosa, \& Lucca, 2005). As pessoas suscetíveis aos riscos de contaminação por agrotóxicos são principalmente aquelas que têm contato no campo, incluindo os de contato direto, tanto os aplicadores, preparadores de caldas e responsáveis por depósitos, como também os trabalhadores de contato indireto ao realizar capinas e colheitas. As medidas de proteção que controlam as exposições ocupacionais aos agrotóxicos devem atuar na prevenção do contato dos produtos com as rotas de entrada do corpo. Em condições de aplicação de agrotóxicos no campo, a principal rota de entrada ocorre na via dérmica e apenas $1 \%$ ou menos na via respiratória (Jaga \& Dharmani, 2003; Londres, 2011).

Minguela e Cunha (2017) afirmaram que a proteção das lavouras é incipiente a própria cultura, sendo uma criação que surgiu para satisfazer muitas necessidades de maneira estável, pois precisa proporcionar alimentos e também produtos de uso comercial e industrial, mas, sobretudo no primeiro caso, em quantidade e qualidade adequadas. Portanto, nada disso seria possível sem uma proteção contínua das lavouras, dentro da qual o emprego dos produtos fitossanitários ocupa um papel muito importante. No que tange ao vento, relata-se que esse fator é de extrema importância na deposição dos defensivos agrícolas aplicados via pulverização, pois a trajetória das partículas liberadas durante a aplicação é influenciada pela distância do alvo, pelo tamanho das gotas e também pela velocidade do vento no momento da aplicação. Nesse contexto, estudos revelaram correlação direta entre o aumento da velocidade do vento e o aumento da deriva. Dessa forma, esse parâmetro meteorológico também é tido como um importante agravador de danos ambientais (Baio, Antuniasse, Castilho, Teodoro, \& Silva, 2019; Langenbach, Mano, Campos, Cunha, \& Campos, 2017; Linhart et al., 2019; Picanço et al., 2014; Shengde et al., 2017; Spadotto, 2006; Wang et al., 2018).

No âmbito da tecnologia de aplicação de defensivos agrícolas, as etiquetas confeccionadas em papel hidrossensível para os experimentos vem sendo significativamente empregadas entre os pesquisadores e produtores, sobretudo para a coleta de informações a respeito da população e do espectro de gotas, que são fundamentais para a calibração dos equipamentos de pulverização e para o sucesso do controle de plantas daninhas, doenças e outras pragas. Por meio da utilização das etiquetas de 
papéis hidrossensíveis é possível obter informações sobre diversos parâmetros importantes que caracterizam a população e o espectro de gotas: o fator de dispersão (Span), a densidade de gotas (gotas $/ \mathrm{cm}^{2}$ ), o diâmetro da mediana volumétrica (DMV), o diâmetro da mediana numérica (DMN), a área de cobertura e a porcentagem de gotas com diâmetro inferior a $100 \mu$ m. Esses parâmetros conjuntamente, determinam a homogeneidade da população de gotas, o diâmetro representativo das gotas produzidas, a área atingida pelo princípio ativo e o potencial de deriva (Baesso, Teixeira, Ruas, \& Baesso, 2014; Oliveira, Vitória, Crause, \& Campanharo, 2019; Vitória \& Campanharo, 2016).

Os papéis utilizados na confecção das etiquetas apresentam a presença da substância bromofenol, que em contato com a água ioniza, ficando o local do contato com a coloração azul. Essa tonalidade contrasta com o amarelo, que é a cor de fundo do papel, de tal modo que permite a caracterização do tamanho e do formato das gotas depositadas na etiqueta (Mewes, Teixeira, Fernandes, Zanuncio, \& Tiburcio, 2015). Os trabalhos efetuados com essas etiquetas têm gerado informações relevantes quanto a: uniformidade das pulverizações, homogeneidade e tamanho das gotas, aplicabilidade de diferentes pontas e equipamentos de pulverização, deposição em diferentes partes dos cultivos e penetração das gotas na região inferior do dossel das culturas, local onde tem início o desenvolvimento de diversas doenças. No entanto, considerando as informações possíveis de serem obtidas por meio dos papéis hidrossensíveis, esses foram utilizados no presente trabalho para avaliação da deposição de defensivos agrícolas sobre o aplicador.

Diante do exposto, o objetivo do manuscrito é avaliar a deposição de defensivos agrícolas sobre o aplicador durante o preparo e a aplicação da calda em condições padronizadas e em condições adversas de vento e vazamento.

\section{Metodologia}

A pesquisa foi desenvolvida no município de Barbacena pertencente ao estado de Minas Gerais. Nesse município o cultivo de rosas é significativo, tornando a cidade conhecida por "Cidade das Rosas". A metodologia utilizada abrange uma pesquisa de campo, envolvendo o levantamento de dados no próprio local onde os fenômenos ocorrem e com o objetivo de conseguir informações sobre um problema através da coleta de dados que se presume serem relevantes para análise (Marconi \& Lakatos, 2017).

Com o objetivo de controle local, conduziu-se a pesquisa em uma casa de vegetação medindo 6,0 x 10,0 x $4,5 \mathrm{~m}$ (largura x comprimento $\mathrm{x}$ altura), com aberturas apenas na parte superior dos lados com menores dimensões. No interior da casa de vegetação, as roseiras, já em fase de floração, possuíam altura entre 1,6 e 2,1 m e canteiros espaçados em aproximadamente $1 \mathrm{~m}$. Avaliou-se a pulverização de dois defensivos agrícolas classificados como orgânicos e utilizados pelos produtores locais, com distintas formulações e ingredientes ativos principais. O defensivo agrícola 1 é utilizado no cultivo de rosas para nutrição, controle de fungos e parasitas, possuindo como ingrediente ativo principal o Cobre $(\mathrm{Cu})$. Já o defensivo agrícola 2, é usado para fins de nutrição, controle de fungos e insetos e possui o Enxofre (S) como ingrediente ativo principal. Na composição de ambos os defensivos foi identificada também a presença de Cálcio (Ca) como ingrediente ativo. Buscando averiguar a situação desfavorável para o aplicador, as avaliações ocorreram nos dias em que o produtor utilizou os produtos na máxima dosagem recomendada pelos fabricantes e misturados.

Para avaliar a deposição de defensivos sobre o aplicador, padronizou-se a utilização do mesmo pulverizador costal manual com tanque de $20 \mathrm{~L}$ e ponta com formato do jato em cone cheio. Para a avaliação da deposição dos produtos sobre o aplicador foram utilizadas etiquetas de papel hidrossensível, sobre os EPIs (Figura 1), posicionadas em 28 partes do corpo do trabalhador (Figura 2), visando a constatação das partes atingidas, bem como das de maior e menor criticidade. 
Figura 1 - Etiquetas posicionadas sobre os EPIs.
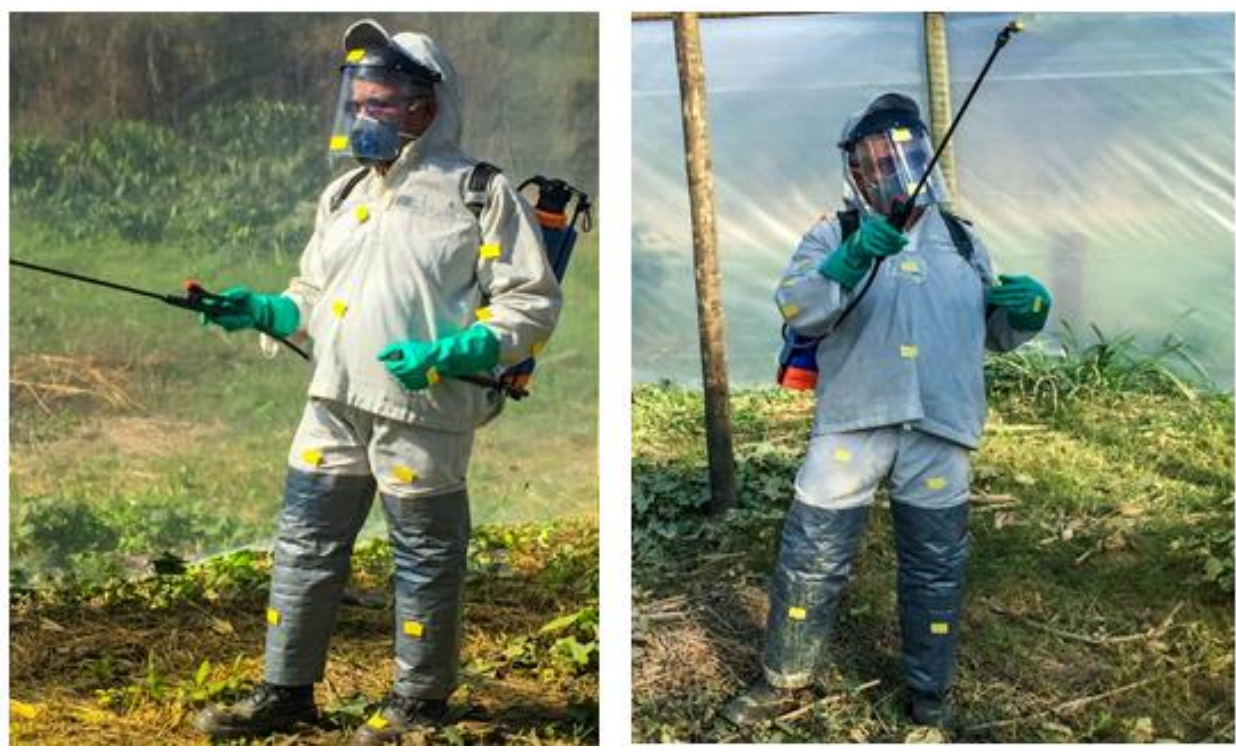

Fonte: Autores (2021).

Ressalta-se que na realização de uma amostra preliminar, nas condições da pesquisa, verificou-se a saturação de algumas etiquetas com volumes de pulverização superiores a 4 L. Portanto, padronizou-se a avaliação durante a aplicação de 4 L de calda em cada repetição do experimento, para que fosse possível a leitura dos resultados pelo software CIR 1.5. Por meio da realização de um ensaio preliminar, constatou-se que não seria possível a utilização de etiquetas hidrossensíveis nas condições de baixa temperatura, tendo em vista que as temperaturas mais baixas também coincidiam com os períodos de maior umidade relativa do ar. Assim, as etiquetas mudavam de cor, absorvendo a umidade ambiente, quando submetidas apenas à exposição local (Figura 3). Logo, a área de cobertura nessas condições não seria adequadamente constatada.

Devido ao acúmulo de umidade no interior das casas de vegetação nas condições de baixa temperatura, ocorria o gotejamento de água da cobertura. Tal fato também comprometeria o resultado de área de cobertura, pois as gotas de água oriundas da cobertura seriam contabilizadas no resultado final. Nesse contexto, padronizou-se a condução do experimento de deposição de defensivos agrícolas sobre o aplicador na condição de temperatura mais elevada (temperatura de bulbo seco acima de $30^{\circ} \mathrm{C}$ ). Realizou-se 8 repetições em dias aleatórios de pulverização, com temperaturas acima de $30^{\circ} \mathrm{C}$, totalizando 224 resultados de deposição sobre o aplicador. Após apurados e organizados, os dados foram representados por meio de imagens e tabelas, e analisados através de medidas de descrição e dispersão com o auxílio dos softwares Excel 2016 e SAEG 9.1 (2007). Também se utilizou os softwares AutoCad 2019 e SigmaPlot 14.0 para gerar os gráficos de distribuição de defensivos agrícolas sobre o aplicador. 
Figura 2 - Partes do corpo humano avaliadas.
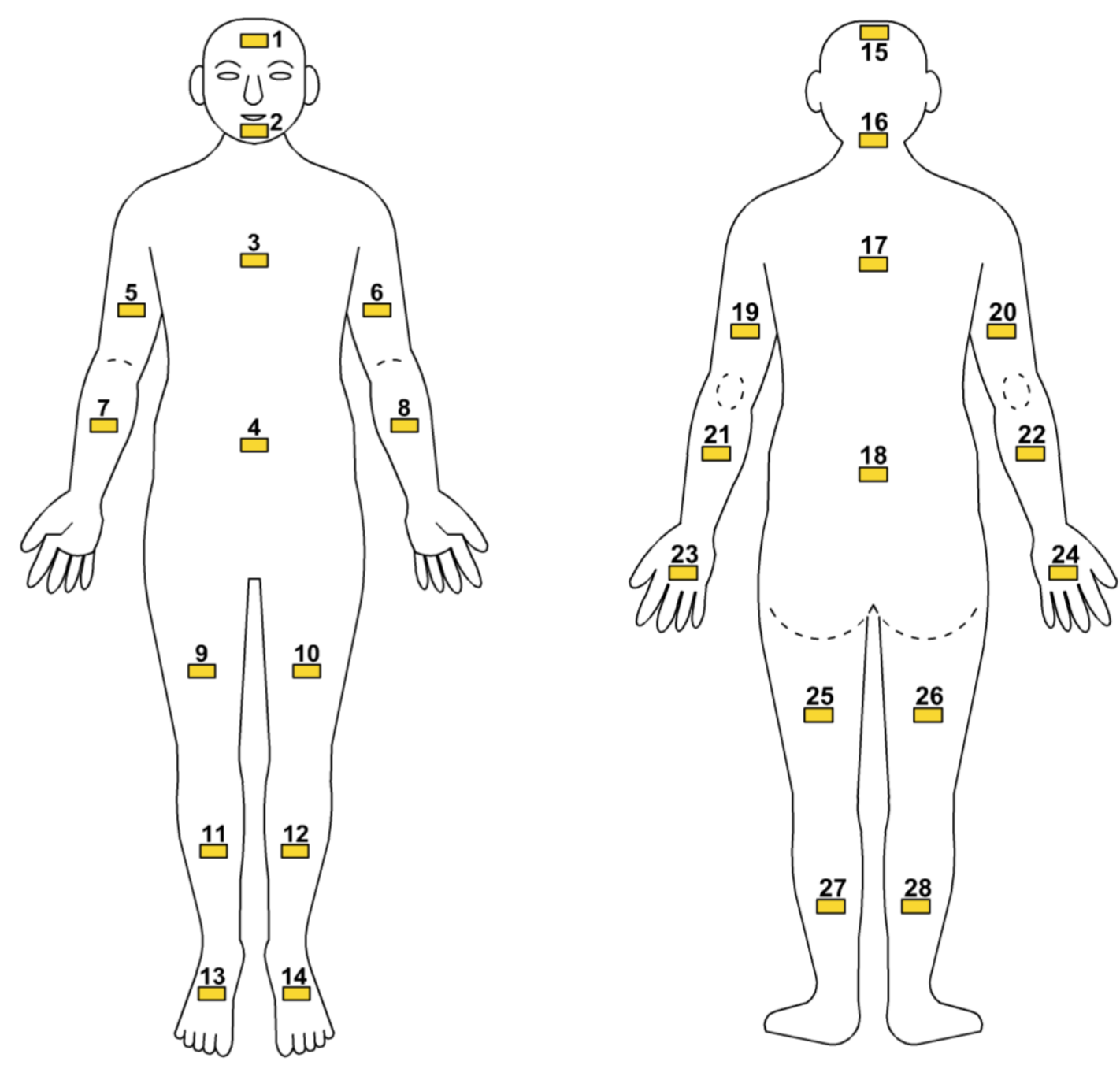

Legenda:

1. Testa

2. Queixo

3. Tórax

4. Abdômen

5. Braço direito anterior

6. Braço esquerdo anterior

7. Antebraço direito anterior

8. Antebraço esquerdo anterior

9. Coxa direita anterior

10. Coxa esquerda anterior

11. Perna direita anterior

12. Perna esquerda anterior

13. Pé direito

14. Pé esquerdo
15. Cabeça (ápice)

16. Pescoço posterior

17. Região torácica posterior

18. Região lombar

19. Braço esquerdo posterior

20. Braço direito posterior

21. Antebraço esquerdo posterior

22. Antebraço direito posterior

23. Mão esquerda

24. Mão direita

25. Coxa esquerda posterior

26. Coxa direita posterior

27. Panturrilha esquerda

28. Panturrilha direita 
Figura 3 - Amostras das etiquetas em condições de baixa temperatura e elevada umidade relativa do ar no interior das casas de vegetação.

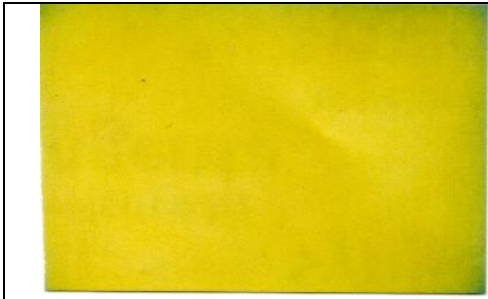

Após 5 minutos no ambiente

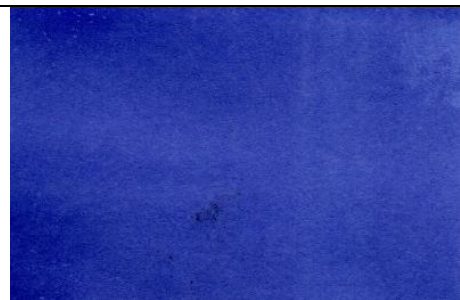

Após 30 minutos no ambiente

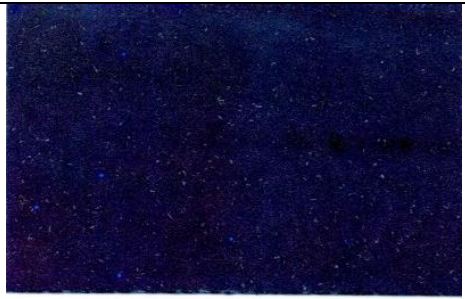

Após 1 hora no ambiente

Fonte: Autores (2021).

\section{Resultados e discussão}

\subsection{Deposição em condições normais de aplicação}

Após a condução do experimento de deposição de defensivos agrícolas sobre o aplicador, obteve-se 8 resultados para cada parte do corpo avaliada, totalizando 224 resultados coletados entre $30,3{ }^{\circ} \mathrm{C}$ e $32,0^{\circ} \mathrm{C}$ em etiquetas de papel hidrossensível. Por meio do software CIR 1.5 determinou-se para todas as amostras: a quantidade de gotas por $\mathrm{cm}^{2}(\overline{Q G})$, o diâmetro da mediana volumétrica $(\overline{D M V})$, o fator de dispersão $(\overline{\operatorname{Span}})$ e área de cobertura $(\overline{A c})$. Assim, na Tabela 1 estão representados os parâmetros expressivos dos resultados encontrados para aplicação de 4 L de calda e nas condições padronizadas de aplicação, ou seja, sem a presença de vento e sem a interferência de possíveis derramamentos de calda do pulverizador costal no operador.

Tabela 1 - Quantidade de gotas por $\mathrm{cm}^{2}$ média $(\overline{Q G})$, diâmetro da mediana volumétrica médio $(\overline{D M V})$, fator de dispersão médio $(\overline{S p a n})$, área de cobertura média $(\overline{A c})$, maior $\left(\mathrm{Ac}_{\text {maior }}\right)$ e menor $\left(\mathrm{Ac}_{\mathrm{menor}}\right)$ valores das áreas de cobertura e coeficiente de variação da área de cobertura $\left(\mathrm{CV}_{\mathrm{Ac}}\right)$ para as partes do corpo avaliadas (continua).

\begin{tabular}{|c|c|c|c|c|c|c|c|}
\hline Parte do corpo & $\begin{array}{c}\overline{Q G} \\
{\left[\operatorname{gotas.cm}^{-2}\right]}\end{array}$ & $\begin{array}{c}\overline{D M V} \\
{[\mu \mathrm{m}]}\end{array}$ & $\overline{\text { Span }}$ & $\begin{array}{l}\overline{\mathbf{A c}} \\
{[\%]}\end{array}$ & $\begin{array}{c}A c_{\text {maior }} \\
{[\%]}\end{array}$ & $\begin{array}{c}\text { Acmenor } \\
{[\%]}\end{array}$ & $\begin{array}{l}C V_{A c} \\
{[\%]}\end{array}$ \\
\hline Abdômen & 442,5 & 83,27 & 1,16 & 6,30 & 10,9 & 3,1 & 48,41 \\
\hline $\begin{array}{c}\text { Antebraço direito } \\
\text { anterior }\end{array}$ & 509,8 & 74,80 & 1,15 & 5,95 & 8,9 & 3,5 & 35,17 \\
\hline $\begin{array}{c}\text { Antebraço direito } \\
\text { posterior }\end{array}$ & 35,0 & 55,79 & 1,26 & 0,20 & 0,4 & 0,0 & 84,52 \\
\hline $\begin{array}{c}\text { Antebraço esquerdo } \\
\text { anterior }\end{array}$ & 242,0 & 72,67 & 1,21 & 2,65 & 5,5 & 0,6 & 72,42 \\
\hline $\begin{array}{c}\text { Antebraço esquerdo } \\
\text { posterior }\end{array}$ & 25,3 & 53,29 & 1,16 & 0,14 & 0,3 & 0,0 & 79,68 \\
\hline Braço direito anterior & 290,3 & 75,72 & 1,18 & 3,80 & 8,7 & 0,6 & 86,14 \\
\hline Braço direito posterior & 21,8 & 61,09 & 1,24 & 0,13 & 0,3 & 0,0 & 93,20 \\
\hline Braço esquerdo anterior & 105,8 & 73,54 & 1,12 & 1,13 & 1,6 & 0,8 & 32,49 \\
\hline
\end{tabular}




\begin{tabular}{|c|c|c|c|c|c|c|c|}
\hline Parte do corpo & $\begin{array}{c}\overline{Q G} \\
{\left[\text { gotas.cm }{ }^{-2}\right]}\end{array}$ & $\begin{array}{c}\overline{D M V} \\
{[\mu \mathrm{m}]}\end{array}$ & $\overline{\text { Span }}$ & $\begin{array}{l}\overline{\mathbf{A c}} \\
{[\%]}\end{array}$ & $\begin{array}{c}A c_{\text {maior }} \\
{[\%]}\end{array}$ & $\begin{array}{c}A c_{m e n o r} \\
{[\%]}\end{array}$ & $\begin{array}{l}C V_{A c} \\
{[\%]}\end{array}$ \\
\hline Braço esquerdo posterior & 112,3 & 72,54 & 1,23 & 1,10 & 1,5 & 0,3 & 46,10 \\
\hline Cabeça (ápice) & 217,3 & 67,85 & 1,19 & 1,95 & 2,7 & 1,4 & 31,13 \\
\hline Coxa direita anterior & 261,8 & 82,27 & 1,16 & 3,48 & 4,3 & 2,7 & 19,01 \\
\hline Coxa direita posterior & 74,8 & 65,45 & 1,38 & 0,63 & 1,3 & 0,1 & 84,99 \\
\hline Coxa esquerda anterior & 129,5 & 78,74 & 1,22 & 1,63 & 2,8 & 0,4 & 59,64 \\
\hline Coxa esquerda posterior & 117,0 & 59,77 & 1,20 & 0,75 & 1,7 & 0,1 & 92,65 \\
\hline Lombar & 77,8 & 57,39 & 1,24 & 0,53 & 1,4 & 0,1 & 105,19 \\
\hline Mão direita & 289,8 & 76,68 & 1,19 & 3,53 & 7,2 & 1,4 & 70,19 \\
\hline Mão esquerda & 98,5 & 69,27 & 1,24 & 0,80 & 1,3 & 0,5 & 41,19 \\
\hline Panturrilha direita & 123,8 & 72,78 & 1,21 & 1,28 & 2,1 & 0,4 & 53,48 \\
\hline Panturrilha esquerda & 103,0 & 67,34 & 1,27 & 0,83 & 1,1 & 0,5 & 32,79 \\
\hline Pé direito & 1191,5 & 108,75 & 1,53 & 32,46 & 36,4 & 25,5 & 13,95 \\
\hline Pé esquerdo & 1313,3 & 84,01 & 1,34 & 26,50 & 36,7 & 14,7 & 31,67 \\
\hline Pescoço posterior & 87,5 & 59,83 & 1,19 & 0,62 & 1,3 & 0,3 & 67,45 \\
\hline Perna direita anterior & 170,5 & 83,45 & 1,16 & 2,53 & 4,5 & 1,1 & 52,40 \\
\hline Perna esquerda anterior & 123,3 & 78,41 & 1,23 & 1,88 & 5,3 & 0,3 & 110,73 \\
\hline Queixo & 253,3 & 75,14 & 1,16 & 3,00 & 4,1 & 1,5 & 36,78 \\
\hline Região torácica posterior & 157,5 & 66,22 & 1,14 & 1,73 & 4,2 & 0,0 & 105,48 \\
\hline Testa & 205,3 & 70,11 & 1,10 & 2,18 & 3,3 & 1,6 & 32,67 \\
\hline Tórax & 390,0 & 77,36 & 1,16 & 5,15 & 9,4 & 2,3 & 61,20 \\
\hline
\end{tabular}

Fonte: Autores (2021).

Por meio da análise da quantidade de gotas foi possível constatar que as partes do corpo atingidas pela maior foram os pés, esquerdo $\left(1313,3\right.$ gotas. $\left.\mathrm{cm}^{-2}\right)$ e direito $\left(1191,5\right.$ gotas. $\left.\mathrm{cm}^{-2}\right)$, seguidos do antebraço direito anterior $(509,8$ gotas. $\left.\mathrm{cm}^{-2}\right)$, abdômen $\left(442,5\right.$ gotas. $\left.\mathrm{cm}^{-2}\right)$ e tórax $\left(390,0\right.$ gotas. $\left.\mathrm{cm}^{-2}\right)$. Em contrapartida, as partes do corpo menos atingidas em quantidade de gotas foram respectivamente: braço direito posterior $\left(21,8\right.$ gotas. $\left.\mathrm{cm}^{2}{ }^{2}\right)$, antebraço esquerdo posterior $(25,3$ gotas. $\left.\mathrm{cm}^{-2}\right)$, antebraço direito posterior $\left(35,0\right.$ gotas. $\left.\mathrm{cm}^{-}\right)$, coxa direita posterior $\left(74,8\right.$ gotas. $\left.\mathrm{cm}^{-2}\right)$ e lombar $\left(77,8\right.$ gotas.cm- $\left.{ }^{2}\right)$, conforme Tabela 1. Quanto ao $\overline{D M V}$ (Tabela 1), obteve-se o maior índice no pé direito (108,75 $\mu \mathrm{m})$ e o menor no antebraço esquerdo posterior $(53,29 \mu \mathrm{m})$. No entanto, destaca-se que $94,64 \%$ do total de $224 \overline{D M V}$ obtidos, foram abaixo de $100 \mu \mathrm{m}$, ou seja, as gotas que atingiram os trabalhadores foram em sua grande maioria classificadas como "muito finas", de acordo com o CIR 1.5, cuja classificação é baseada na norma ASAE S572. 
Em relação ao $(\overline{\operatorname{Span}})$, que segundo Baesso et al. (2014) caracteriza a variação/homogeneidade do tamanho das gotas, conforme apresentado na Tabela 1, obteve-se o grupo de gotas mais homogêneos na testa $(\overline{\operatorname{Span}}=1,1)$ e o grupo menos homogêneo no pé direito $(\overline{\operatorname{Span}}=1,53)$. Contudo, considerando que todos os $\overline{\operatorname{Span}}$ das amostras variaram entre $1,0 \mathrm{e}$ 1,9, estando assim, muito próximos de 1 , constatou-se que as gotas que chegam aos aplicadores durante a aplicação dos defensivos foram consideravelmente homogêneas. No que tange a área de cobertura, ou seja, o percentual de área atingida pela calda, contatou-se que, em média, as cinco partes do corpo mais afetadas foram: $1^{\circ}$ ) Pé direito $-32,46 \%, 2^{\circ}$ ) Pé esquerdo 26,50\%, $3^{\circ}$ ) Abdômen $-6,30 \%, 4^{\circ}$ ) Antebraço direito anterior - 5,95\% e $5^{\circ}$ ) Tórax - 5,15\%. Por outro lado, as cinco partes menos atingidas foram: $28^{\circ}$ ) Braço direito posterior $-0,13 \%, 27^{\circ}$ ) Antebraço esquerdo posterior $-0,14 \%, 26^{\circ}$ ) Antebraço direito posterior $-0,20 \%, 25^{\circ}$ ) Lombar $-0,53 \%$ e $24^{\circ}$ ) Pescoço posterior - 0,62\%. Na Tabela 1 e nas Figura 4 e 5 estão demonstrados esses resultados.

Ainda de acordo com a Tabela 1, dos 224 resultados de área de cobertura, o maior valor obtido foi de 36,7\% (pé esquerdo) e o menor valor foi zero (antebraço direito e esquerdo posteriores, braço direito posterior e na região torácica posterior). De acordo com o coeficiente de variação da área de cobertura, obteve-se o conjunto de amostras mais homogêneo no pé direito $(13,95 \%)$ e o conjunto de amostras mais disperso na perna esquerda anterior (110,73\%).

Nesse contexto, observou-se que as cinco partes do corpo mais atingidas foram frontais (anteriores) e em contrapartida, as cinco partes menos atingidas foram posteriores. Tal fato pode ser explicado pelas partes frontais estarem mais próximas do bico de pulverização e, portanto, mais susceptíveis aos impactos das gotas. Deste modo, foi possível constatar que a aplicação de defensivos agrícolas em casas de vegetação com pulverizador costal manual propiciou a deposição de calda nas 28 partes do corpo avaliadas. Logo, os resultados desse estudo demonstraram que a aplicação de defensivos agrícolas, por meio da utilização de pulverizador costal manual, demanda a utilização de EPIs (Equipamentos de Proteção Individual) capazes de neutralizar a exposição à agentes químicos para todas as partes do corpo dos aplicadores, de forma a promover a adequada segurança ocupacional. Corroborando a contaminação de partes do corpo e a necessidade de proteção adequada dos trabalhadores, Baldi et al. (2014), destacaram que o contato físico com ramos, folhas, frutas ou legumes em culturas previamente tratadas é responsável pela transferência de defensivos agrícolas para a pele do trabalhador em diversas tarefas agrícolas.

Assim, em pesquisa realizada por esses autores numa região de vinhedos em Bordeaux, na França, com a coleta de amostras diretamente sobre a pele, embaixo das roupas regulares e EPIs, constatou-se que nas atividades de reentrada em vinhas com aplicação prévia de defensivos agrícolas foram observados os níveis mais altos de contaminação dérmica sobre os antebraços, braços e coxas. Durante a colheita, os antebraços foram os membros mais contaminados. Além disso, os pesquisadores também observaram que a maior contaminação foi observada quando a temperatura máxima aumentou. Em contrapartida, um estudo envolvendo possíveis efeitos genotóxicos em floricultores no sul do Brasil, demonstrou que o uso de EPI completo, incluindo macacão, luvas, botas, máscara, óculos de proteção e proteção da cabeça, foi relatado por 45,9\% dos trabalhadores e apenas no momento da aplicação de defensivos agrícolas. Apontou-se ainda, que os floricultores estavam expostos a misturas de defensivos com potencial genotóxico, ou seja, com capacidade de ação sobre o DNA (Wilhelm, Calsing, \& Silva, 2015). 
Research, Society and Development, v. 11, n. 1, e24311124889, 2022

(CC BY 4.0) | ISSN 2525-3409 | DOI: http://dx.doi.org/10.33448/rsd-v11i1.24889

Figura 4 - Amostras das partes do corpo mais e menos atingidas em relação a $\overline{A c}$.

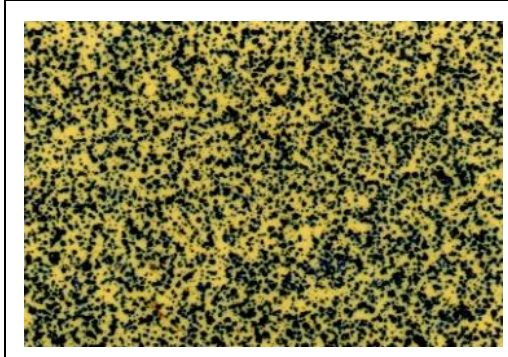

Pé direito (Repetição 05)

$$
\mathrm{Ac}=\mathbf{3 6 , 4 \%}
$$

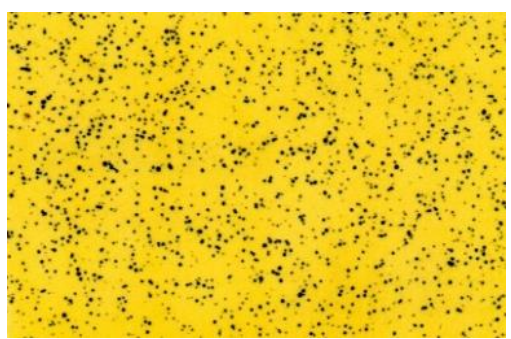

Antebraço direito anterior (Repetição 04)

$$
\text { Ac }=8,9 \%
$$

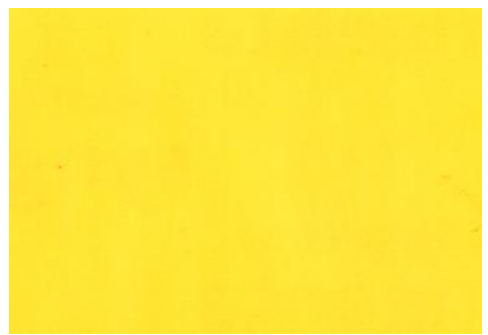

Braço direito posterior

(Repetição 07)

Ac $=0$

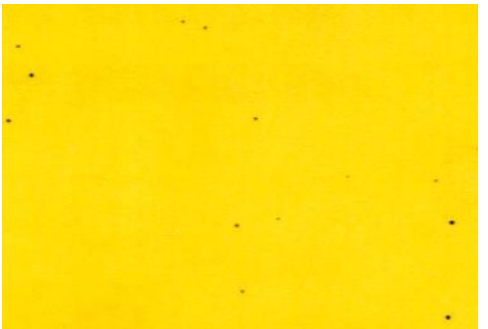

Lombar (Repetição 01)

$\mathrm{Ac}=1,4 \%$

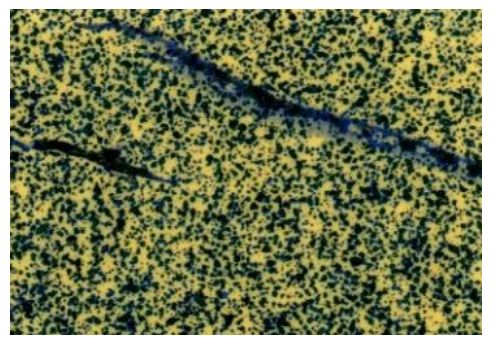

Pé Esquerdo (Repetição 05)

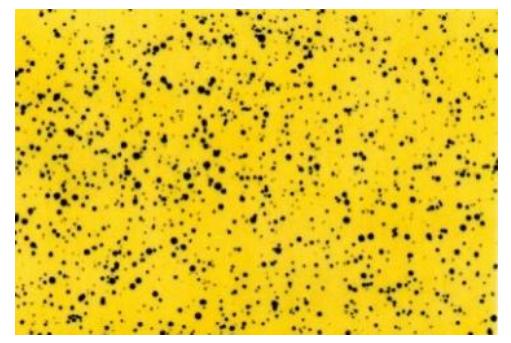

Abdômen (Repetição 08)

$\mathrm{Ac}=10,9 \%$

$$
\mathrm{Ac}=36,7 \%
$$

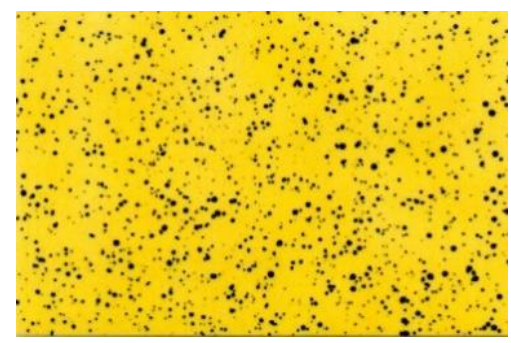

Tórax (Repetição 08)

$$
\mathrm{Ac}=\mathbf{9 , 4 \%}
$$

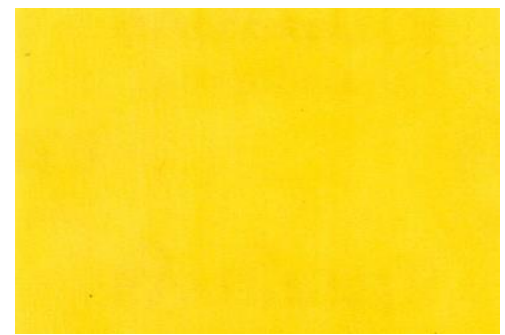

Antebraço direito posterior (Repetição 04)

Ac $=0$

\section{(Repetição 06)}

Ac $=0,1 \%$

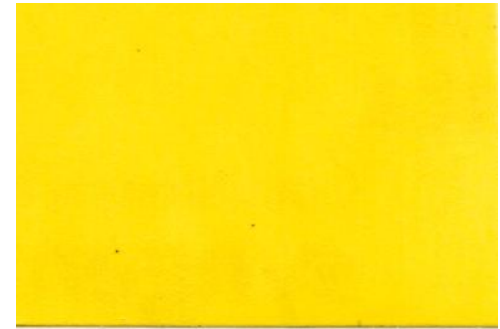

Pescoço posterior (Repetição 02)

$\mathrm{Ac}=\mathbf{0 , 4 \%}$

Fonte: Autores (2021). 
Figura 5 - Distribuição da área de cobertura de defensivos agrícolas sobre o aplicador aplicados com pulverizador costal em casas de vegetação.

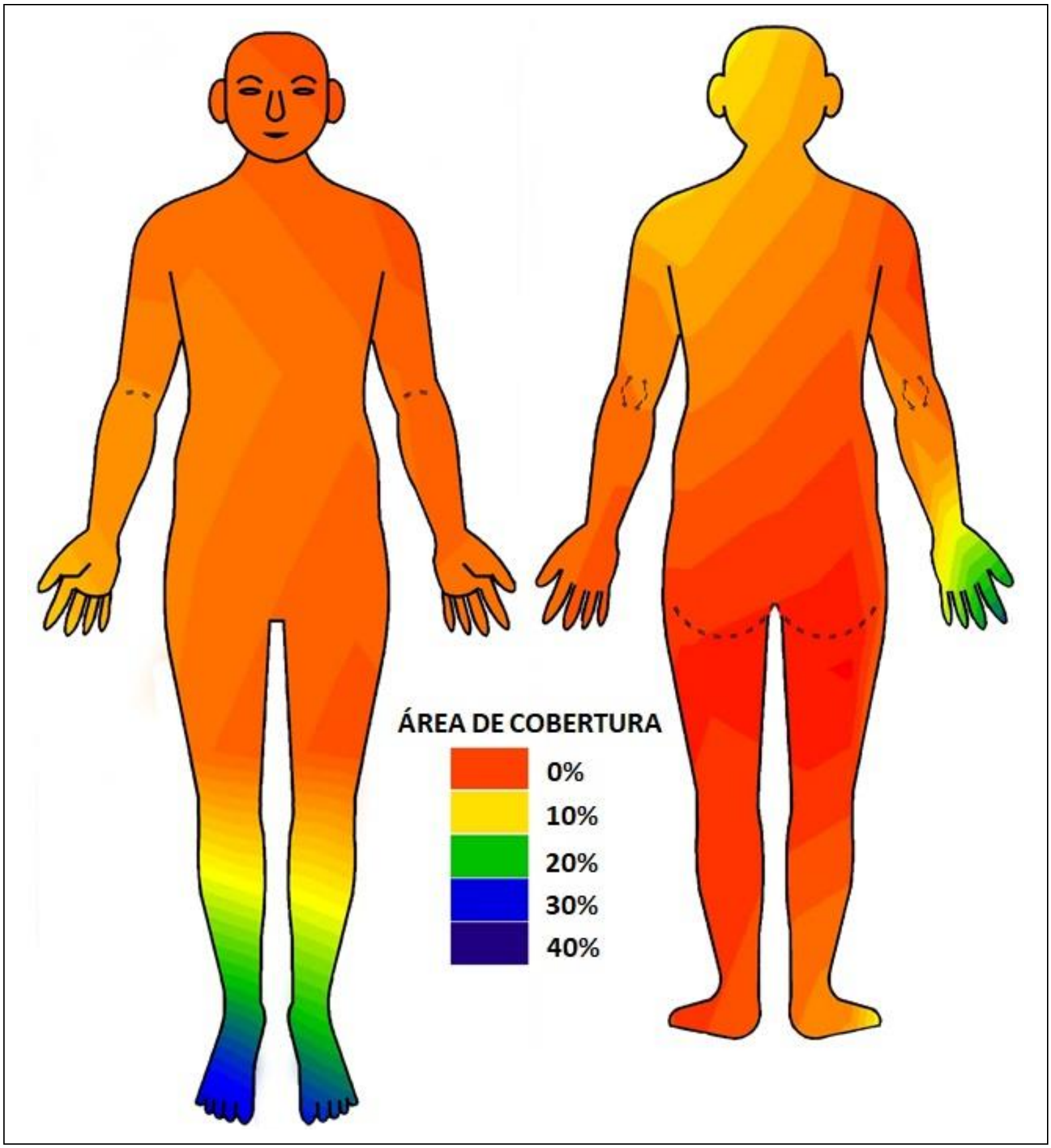

Fonte: Autores (2021).

\subsection{Deposição em condições de vento e vazamento}

Ao longo da condução do experimento de deposição de defensivos agrícolas sobre o aplicador, apesar de terem sido padronizadas inicialmente as condições de coleta de dados, quatro repetições precisaram ser refeitas devido a interferências não planejadas envolvendo a presença de ventos de até 0,9 m.s-1 no interior das casas de vegetação e vazamentos de calda do pulverizador costal no operador. Assim, apesar dessas amostras sob condições adversas não terem sido consideradas nos resultados de deposição de defensivos agrícolas sobre o aplicador demonstrados anteriormente, cabe destacar o impacto dessas condições observadas em campo sobre a deposição nos aplicadores.

Nesse contexto, em relação à incidência de vento no interior das casas de vegetação durante a etapa de aplicação de 
defensivos agrícolas do experimento, tendo como base os resultados demonstrados na Tabela 2, constatou-se ao nível de 5\% de probabilidade que 23 das 28 partes do corpo humano avaliadas tiveram os parâmetros aumentados de forma significativa em relação aos experimentos conduzidos sem a presença de vento. Nesse sentido, a $\overline{Q G}$ foi estatisticamente maior em 13 das 28 partes do corpo avaliadas, sendo as partes mais atingidas nessa condição os pés, direito (1348,0 gotas.cm-2 $)$ e esquerdo $\left(1121,0\right.$ gotas.cm $\left.{ }^{-2}\right)$, seguidos do antebraço direito anterior $\left(554,5\right.$ gotas.cm $\left.{ }^{-2}\right)$, perna direita anterior $\left(529,0\right.$ gotas.cm $\left.{ }^{-2}\right)$ e mão direita $\left(512,0\right.$ gotas. $\left.\mathrm{cm}^{-2}\right)$.

No que se refere ao $\overline{D M V}$ (Tabela 2), em 22 partes do corpo houve o aumento estatisticamente significativo desse parâmetro, sendo o maior $\overline{D M V}$ obtido na mão esquerda $(158,56 \mu \mathrm{m})$ e o menor, assim como na condição sem vento, no antebraço esquerdo posterior $(48,22 \mu \mathrm{m})$. Ademais, na presença de vento, apenas $49 \%$ das amostras apresentaram $\overline{D M V}$ abaixo de $100 \mu \mathrm{m}$, sendo essas classificadas como "muito finas" e as demais (51\%) como "finas". Ou seja, quando comparado à condição de aplicação sem vento, onde o percentual de amostras classificadas como "muito finas" foi de 94,64\%, houve o aumento do tamanho das gotas que atingiram os aplicadores na presença de vento, conforme demonstrado também na Figura 66.

Tabela 2 - Quantidade de gotas por $\mathrm{cm}^{2}$ média $(\overline{Q G})$, diâmetro da mediana volumétrica médio $(\overline{D M V})$, fator de dispersão médio $\left(\overline{S_{p a n}}\right)$, área de cobertura média $(\overline{A c})$ e resultado do Teste "t" unilateral $(\mathrm{P}<0,05)$ sob a incidência de vento para as partes do corpo avaliadas.

\begin{tabular}{|c|c|c|c|c|c|}
\hline Parte do corpo & $\begin{array}{c}\overline{Q G} \\
{\left[\text { gotas.cm }^{-2}\right]}\end{array}$ & $\overline{D M V}$ & $\overline{\text { Span }}$ & $\overline{\mathbf{A c}}$ & $\begin{array}{c}\text { Parâmetros } \\
\text { aumentados pela } \\
\text { incidência de vento } \\
(P<0,05)\end{array}$ \\
\hline Abdômen & 349,0 & 125,66 & 1,36 & 11,70 & $\overline{Q G}, \overline{D M V}, \overline{\operatorname{Span}}, \overline{\mathrm{Ac}}$ \\
\hline $\begin{array}{c}\text { Antebraço direito } \\
\text { anterior }\end{array}$ & 554,5 & 129,30 & 1,38 & 16,15 & $\overline{\mathrm{DMV}}, \overline{\operatorname{Span}}, \overline{\mathrm{Ac}}$ \\
\hline $\begin{array}{c}\text { Antebraço direito } \\
\text { posterior }\end{array}$ & 34,0 & 84,11 & 1,83 & 0,30 & $\overline{D M V}, \overline{\text { Span }}$ \\
\hline $\begin{array}{c}\text { Antebraço esquerdo } \\
\text { anterior }\end{array}$ & 253,0 & 128,44 & 1,66 & 5,65 & $\overline{D M V}, \overline{\operatorname{Span}}, \overline{\mathrm{Ac}}$ \\
\hline $\begin{array}{c}\text { Antebraço esquerdo } \\
\text { posterior }\end{array}$ & 14,5 & 48,22 & 1,10 & 0,10 & $\mathrm{X}$ \\
\hline Braço direito anterior & 406,0 & 123,54 & 1,24 & 11,65 & $\overline{D M V}, \overline{\operatorname{Span}}, \overline{\mathrm{Ac}}$ \\
\hline Braço direito posterior & 173,0 & 81,98 & 1,42 & 2,20 & $\overline{Q G}, \overline{D M V}, \overline{\operatorname{Span}}, \overline{\mathrm{Ac}}$ \\
\hline Braço esquerdo anterior & 281,0 & 89,62 & 1,29 & 6,0 & $\overline{Q G}, \overline{D M V}, \overline{\operatorname{Span}}, \overline{\mathrm{Ac}}$ \\
\hline Braço esquerdo posterior & 165,5 & 104,17 & 1,35 & 3,45 & $\overline{Q G}, \overline{D M V}, \overline{\mathrm{Ac}}$ \\
\hline Cabeça (ápice) & 335,0 & 98,94 & 1,24 & 4,05 & $\overline{Q G}, \overline{D M V}, \overline{\mathrm{Ac}}$ \\
\hline Coxa direita anterior & 153,0 & 141,00 & 1,94 & 5,90 & $\overline{D M V}, \overline{\operatorname{Span}}, \overline{\mathrm{Ac}}$ \\
\hline
\end{tabular}




\begin{tabular}{|c|c|c|c|c|c|}
\hline Parte do corpo & $\begin{array}{c}\overline{Q G} \\
{\left[\text { gotas.cm }{ }^{-2}\right]}\end{array}$ & $\begin{array}{c}\overline{D M V} \\
{[\mu \mathrm{m}]}\end{array}$ & $\overline{\text { Span }}$ & $\begin{array}{l}\overline{\mathbf{A c}} \\
{[\%]}\end{array}$ & $\begin{array}{c}\text { Parâmetros } \\
\text { aumentados pela } \\
\text { incidência de vento } \\
(P<0,05)\end{array}$ \\
\hline Coxa direita posterior & 71,0 & 55,48 & 1,22 & 0,45 & $\mathrm{X}$ \\
\hline Coxa esquerda anterior & 119,0 & 149,86 & 2,02 & 2,70 & $\overline{\mathrm{DMV}}, \overline{\mathrm{Span}}, \overline{\mathrm{Ac}}$ \\
\hline Coxa esquerda posterior & 33,5 & 56,00 & 1,17 & 0,25 & $\mathrm{X}$ \\
\hline Lombar & 58,00 & 68,92 & 1,37 & 0,45 & $\mathrm{X}$ \\
\hline Mão direita & 512,0 & 128,19 & 1,51 & 13,00 & $\overline{Q G}, \overline{D M V}, \overline{\operatorname{Span}}, \overline{\mathrm{Ac}}$ \\
\hline Mão esquerda & 110,0 & 158,56 & 2,51 & 1,20 & $\overline{\mathrm{DMV}}, \overline{\mathrm{Span}}, \overline{\mathrm{Ac}}$ \\
\hline Panturrilha direita & 103,0 & 68,3 & 1,21 & 0,95 & $X$ \\
\hline Panturrilha esquerda & 317,5 & 70,01 & 1,30 & 2,60 & $\overline{Q G}, \overline{\mathrm{Ac}}$ \\
\hline Pé direito & 1348,0 & 123,42 & 1,71 & 36,4 & $\overline{Q G}, \overline{D M V}, \overline{\operatorname{Span}}, \overline{\mathrm{Ac}}$ \\
\hline Pé esquerdo & 1121,0 & 111,50 & 1,54 & 28,32 & $\overline{D M V}, \overline{S p a n}$ \\
\hline Pescoço posterior & 129,0 & 91,78 & 1,28 & 2,50 & $\overline{Q G}, \overline{D M V}, \overline{S p a n}, \overline{\mathrm{Ac}}$ \\
\hline Perna direita anterior & 529,0 & 100,89 & 1,16 & 11,10 & $\overline{Q G}, \overline{D M V}, \overline{A C}$ \\
\hline Perna esquerda anterior & 344,0 & 103,27 & 1,29 & 5,85 & $\overline{Q G}, \overline{D M V}, \overline{A C}$ \\
\hline Queixo & 414,0 & 118,18 & 1,26 & 11,15 & $\overline{Q G}, \overline{D M V}, \overline{\operatorname{Span}}, \overline{\mathrm{Ac}}$ \\
\hline Região torácica posterior & 246,0 & 82,45 & 1,23 & 3,50 & $\overline{D M V}, \overline{\mathrm{Ac}}$ \\
\hline Testa & 311,0 & 111,13 & 1,39 & 6,9 & $\overline{Q G}, \overline{D M V}, \overline{\operatorname{Span}}, \overline{\mathrm{Ac}}$ \\
\hline Tórax & 348,0 & 118,35 & 1,29 & 11,40 & $\overline{\mathrm{DMV}}, \overline{\mathrm{Span}}, \overline{\mathrm{Ac}}$ \\
\hline
\end{tabular}

Fonte: Autores (2021).

Quanto ao $\overline{\operatorname{Span}}$, conforme apresentado na Tabela 2, 17 partes do corpo tiveram tal parâmetro maior nessa condição adversa, indicando que a presença de vento também reduziu a homogeneidade das gotas que atingiram os aplicadores. Nessas condições, obteve-se o grupo de gotas mais homogêneos no antebraço esquerdo posterior $(\overline{\operatorname{Span}}=1,1)$ e o grupo menos homogêneo na mão esquerda $(\overline{\operatorname{Span}}=2,51)$.

Para a área de cobertura média, constatou-se que em 21 partes do corpo houve o aumento estatisticamente significativo desse parâmetro nas condições de incidência de vento, sendo as maiores variações, comparada às condições sem vento, observadas no braço direito posterior (1592,3\%), no braço esquerdo anterior (431,0\%) e na perna direita anterior $(338,74 \%)$. Ainda em relação a $\overline{A c}$, sob a presença de vento no momento da aplicação constatou-se que as cinco parte do corpo mais afetadas foram: $1^{\circ}$ ) Pé direito - 36,4\%, $2^{\circ}$ ) Pé esquerdo - 28,32\%, $3^{\circ}$ ) Antebraço direito anterior - 16,15\%, $4^{\circ}$ ) Mão direita - 13,0\% e 5 $5^{\circ}$ Abdômen - 11,7\%. Na Tabela 2 e nas Figura 6 e 7 estão demonstrados esses resultados. 
Com base nos resultados da Tabela 2, constatou-se que também sob condições de vento as 5 partes do corpo mais atingidas foram frontais (anteriores) e as 5 partes menos atingidas foram posteriores: antebraço esquerdo posterior $(0,1 \%)$, coxa esquerda posterior $(0,25 \%)$, antebraço direito posterior $(0,3 \%)$, coxa direita posterior $(0,45 \%)$ e lombar $(0,45 \%)$.

Figura 6 - Comparativo de amostras de partes do corpo em condições com e sem vento.

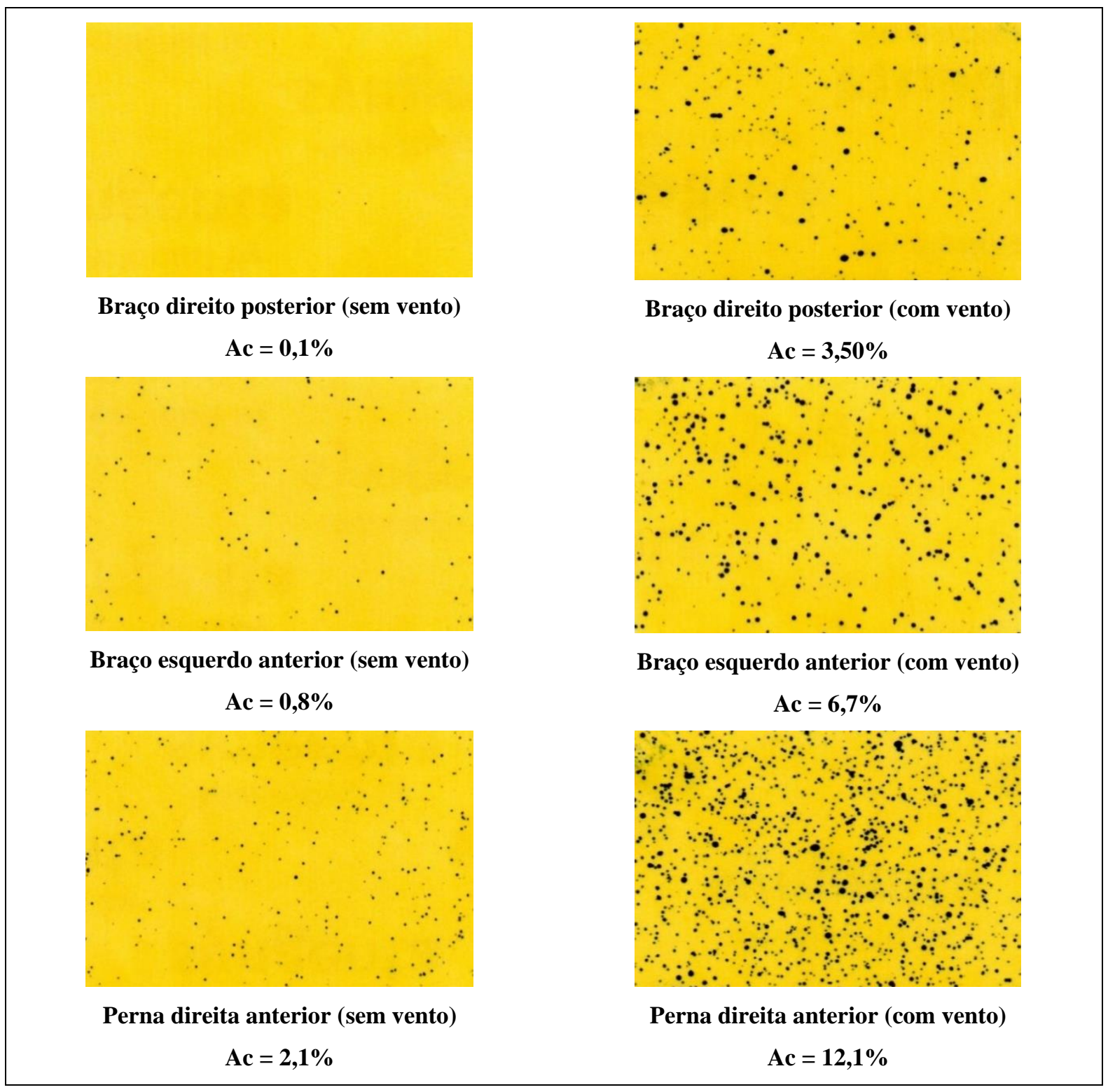

Fonte: Autores (2021). 
Figura 7 - Distribuição da área de cobertura de defensivos agrícolas sobre o aplicador aplicados com pulverizador costal em casas de vegetação em condições de incidência de vento.

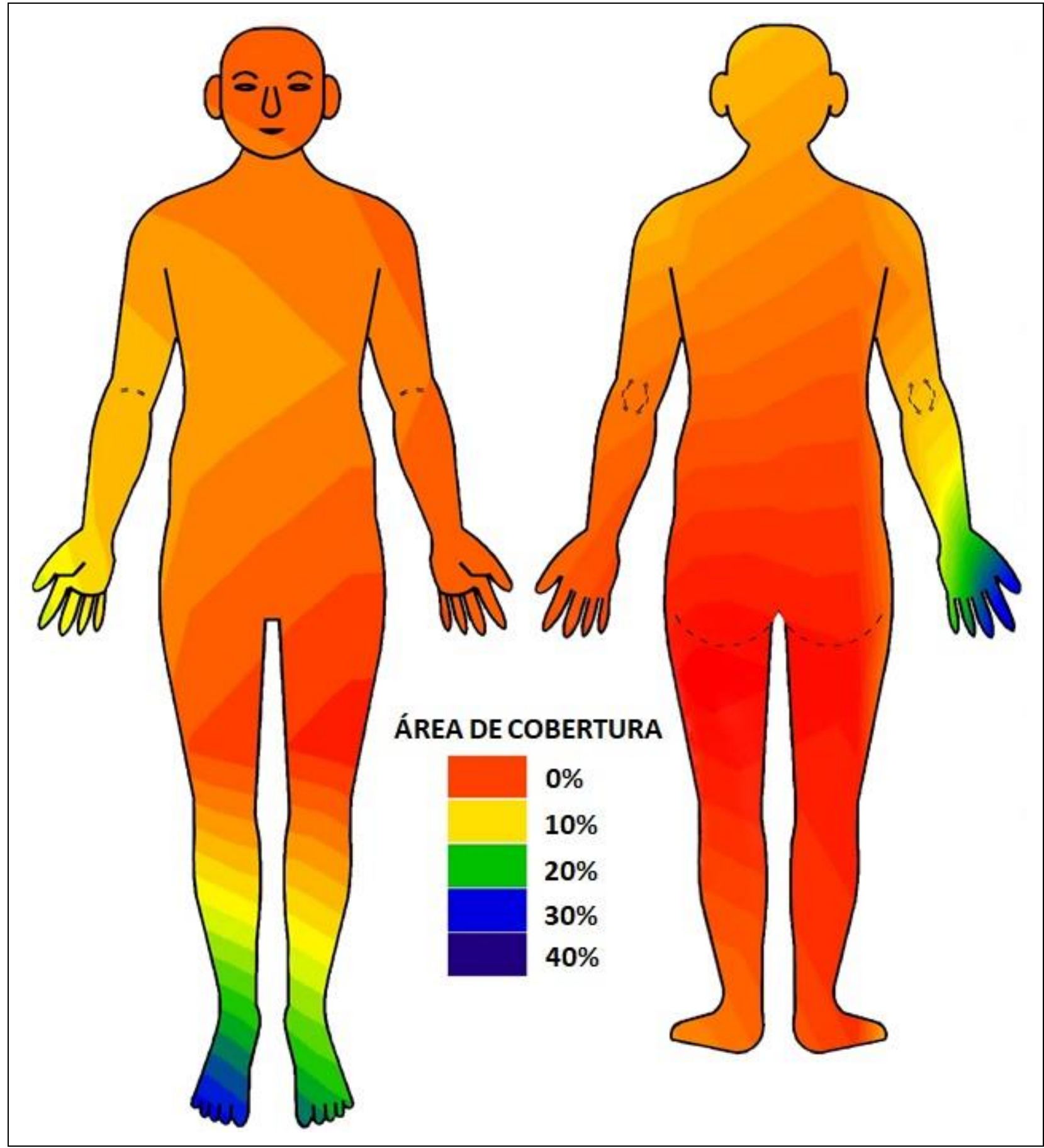

Fonte: Autores (2021)

Em relação à ocorrência de vazamentos de calda do pulverizador costal nos operadores, em duas repetições do experimento observou-se tal acontecimento. A primeira ocorrência se deu na conexão da alavanca de acionamento com o tanque do pulverizador (Figura 8). Já a outra, pela própria tampa do tanque do equipamento.

No primeiro caso, as partes do corpo mais atingidas pela calda oriunda do vazamento foram a panturrilha esquerda e a coxa esquerda posterior, conforme demonstrado na Figura 9 pelas etiquetas hidrossensíveis coletadas nesses locais com área de cobertura de $23,2 \%$ e $8,1 \%$ respectivamente. Em contrapartida, no segundo caso, as partes mais atingidas foram a panturrilha 
Research, Society and Development, v. 11, n. 1, e24311124889, 2022

(CC BY 4.0) | ISSN 2525-3409 | DOI: http://dx.doi.org/10.33448/rsd-v11i1.24889

esquerda $(\overline{A C}=47,5 \%)$ e a região torácica posterior $(\overline{A C}=1,6 \%)$, vide Figura 10.

Figura 8 - Derramamento de calda na conexão da alavanca de acionamento com o tanque do pulverizador.

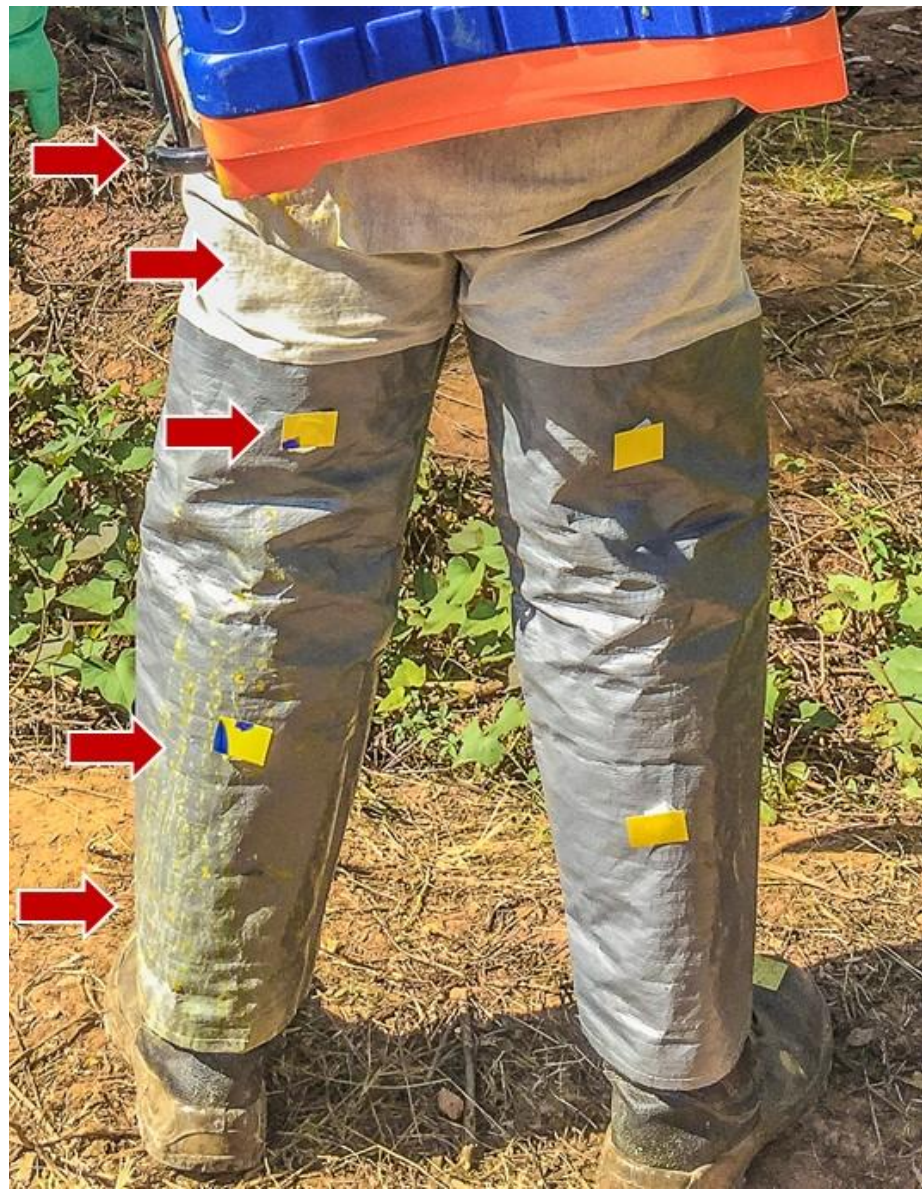

Fonte: Autores (2021).

Figura 9 - Etiquetas hidrossensíveis afetadas pelo vazamento de calda na conexão da alavanca de acionamento com o tanque do pulverizador costal manual.

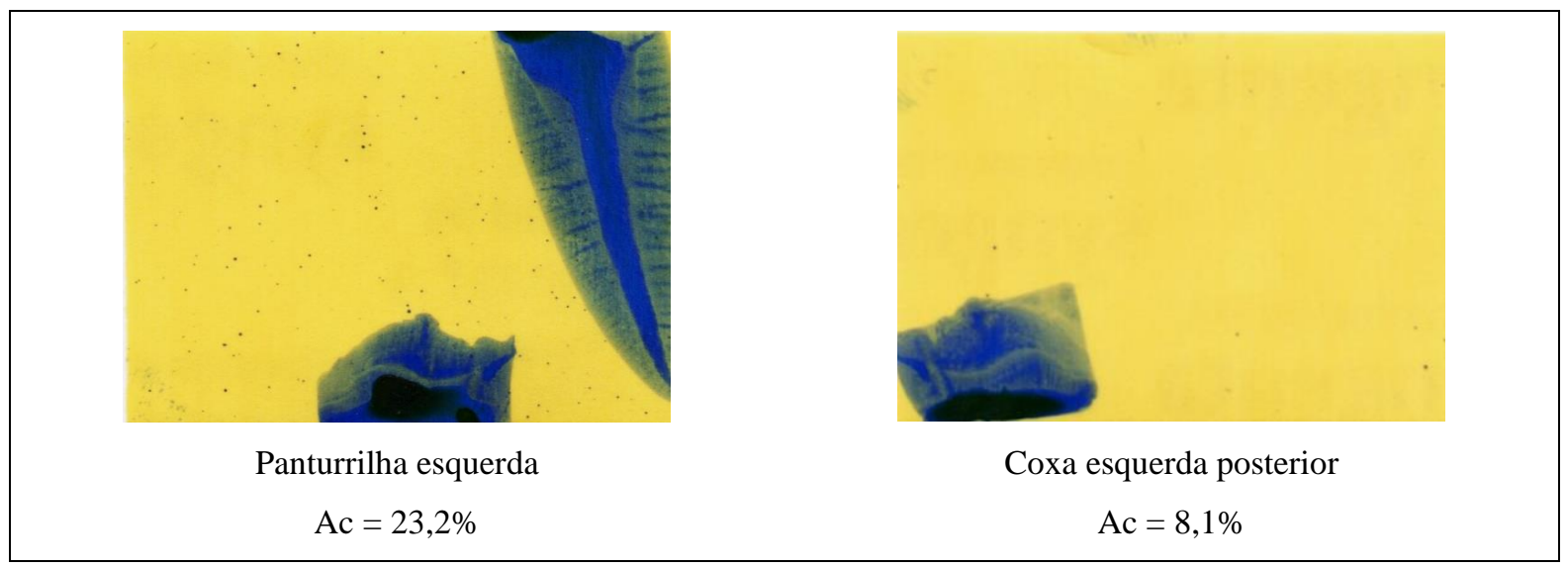

Fonte: Autores (2021). 
Research, Society and Development, v. 11, n. 1, e24311124889, 2022

(CC BY 4.0) | ISSN 2525-3409 | DOI: http://dx.doi.org/10.33448/rsd-v11i1.24889

Figura 10 - Etiquetas hidrossensíveis afetadas pelo vazamento de calda pela tampa do pulverizador costal manual.

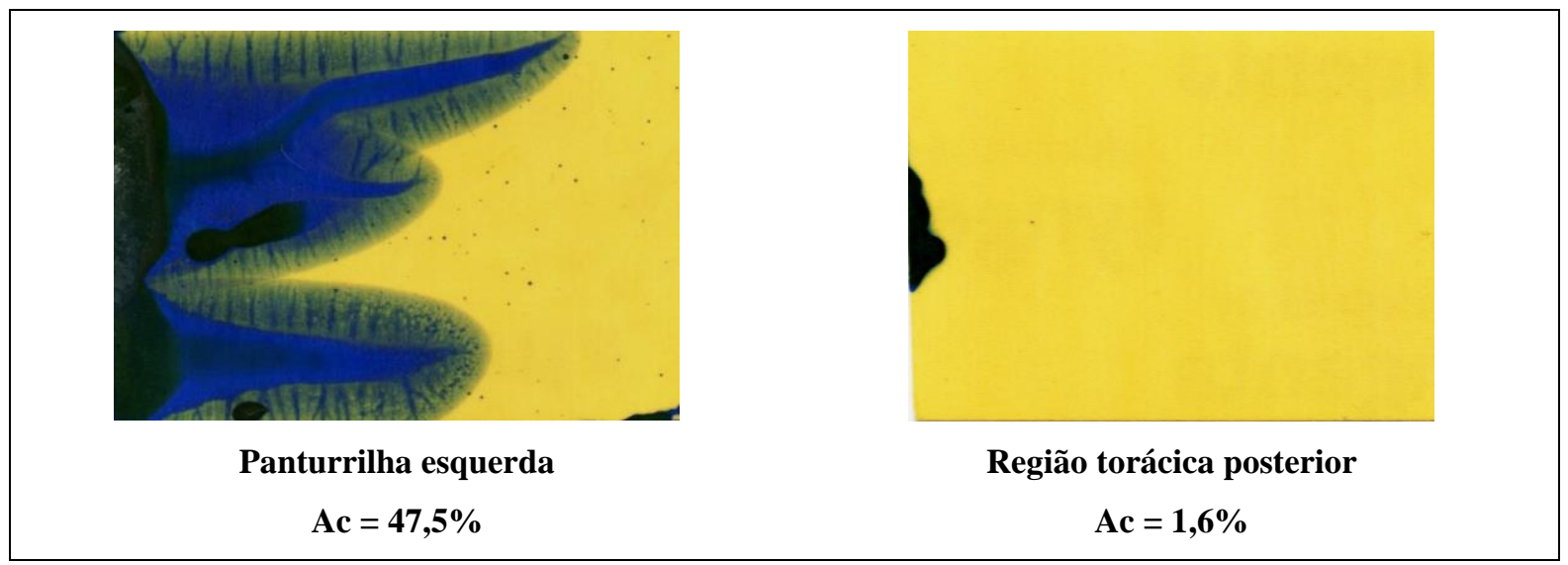

Fonte: Autores (2021).

Também se observou que alguns aplicadores ao pausarem a aplicação permitiram o gotejamento de calda sobre os pés ao acidentalmente baixarem a haste de aplicação em direção a eles, conforme demonstrado na Figura 111 pelas etiquetas hidrossensíveis coletadas nesses locais com suas respectivas áreas de cobertura.

Assim, a ocorrência de vazamentos e gotejamentos acidentais demonstram que, além da necessidade de observância contínua de funcionamento e manutenção dos equipamentos de aplicação de defensivos agrícolas, deve-se promover a conscientização a respeito do fornecimento e utilização de EPIs adequadamente impermeáveis, capazes de proteger os operadores em condições de vazamentos e gotejamento acidental de calda.

Figura 11 - Etiquetas hidrossensíveis afetadas pelo gotejamento de calda sobre os pés.

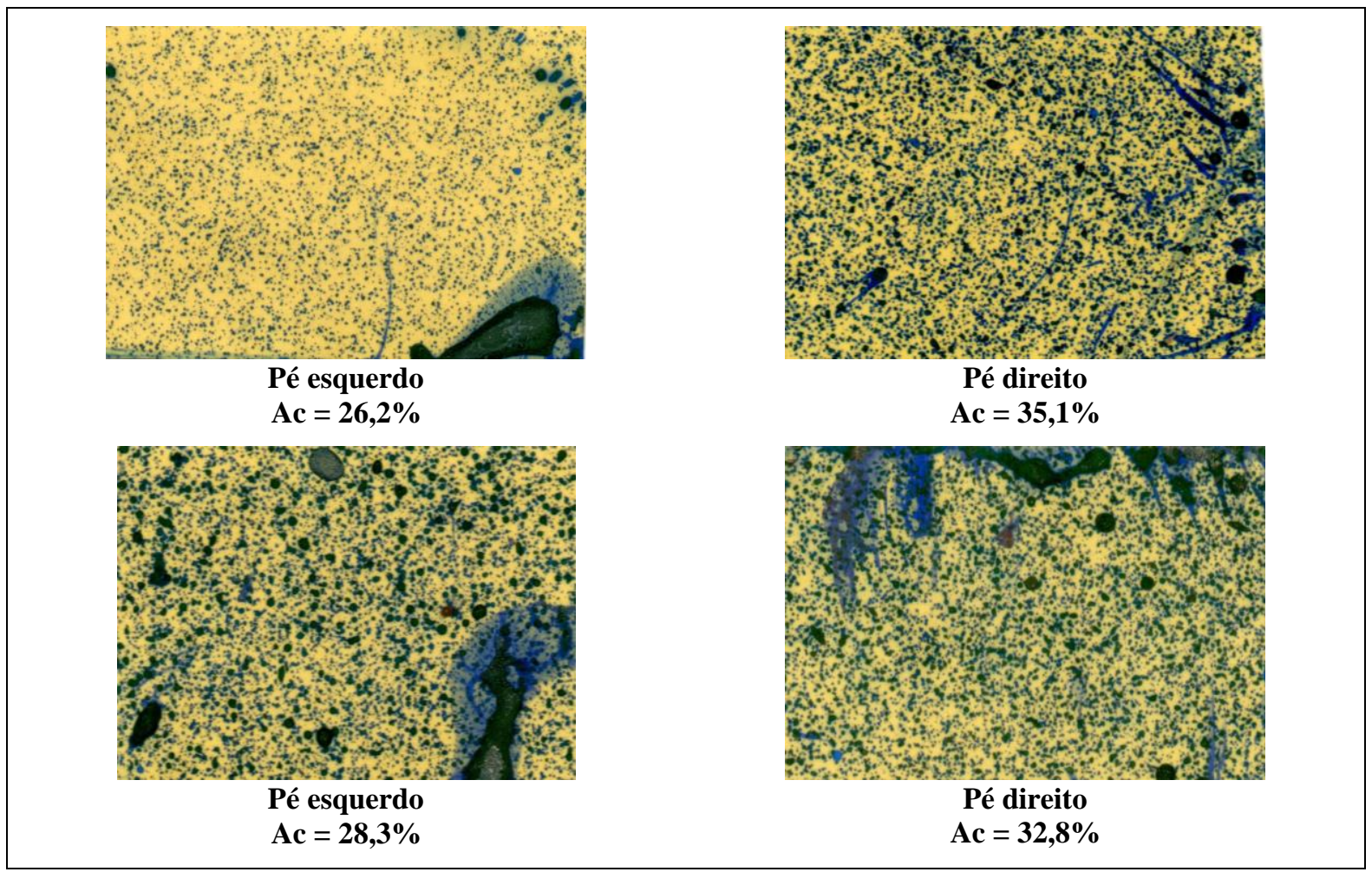

Fonte: Autores (2021). 


\subsection{Insalubridade e deposição sobre o aplicador}

Cabe destacar que, em relação à insalubridade, a Norma Regulamentadora $\mathrm{n}^{\circ} 15$ do Ministério do Trabalho e Previdência, não estabelece limites de tolerância para a deposição de agentes químicos sobre a pele, não sendo, portanto, definidos também graus e percentuais de adicionais de insalubridade nesse sentido. Os limites de tolerância que constam no Anexo n 11 da NR-15 são válidos apenas para absorção por vias respiratórias. Por outro lado, esse mesmo anexo indica alguns agentes químicos que podem ser absorvidos por via cutânea e, portanto, carecem de EPIs adequados para esse fim. Contudo, nenhum dos agentes químicos avaliados são indicados nessa legislação com potencial de absorção cutânea (Brasil, 2019b).

No entanto, o fato de não haver adicional de insalubridade regulamentado para deposição sobre a pele e de muitos agentes químicos não estarem indicados com potencial de absorção por via cutânea, não exime os trabalhadores de possíveis efeitos danosos envolvendo a exposição aos defensivos agrícolas. Pois além do Anexo $\mathrm{n}^{\mathrm{o}} 11$ possuir limites de tolerância e agentes químicos desatualizados em relação aos limites internacionalmente utilizados, trata-se de uma regulamentação para fins de pagamento de adicional de insalubridade. Assim, não abrange os efeitos danosos dos agentes químicos e não desobriga que medidas de controle sejam implantadas para a preservação da saúde dos trabalhadores.

Ressalta-se ainda, que as próprias FISPQs (Ficha de Informações de Segurança de Produtos Químicos) dos defensivos agrícolas avaliados abrangem frases de perigo que mencionam nocividade em relação à exposição sem medidas de controle adequada, tais como: "Nocivo se ingerido", "Provoca irritação moderada à pele", "Provoca irritação ocular", "Pode provocar lesões alérgicas na pele".

Corroborando as explanações, Moraes (2010) citou que 80\% dos casos de dermatoses ocupacionais são causadas por agente químicos presentes nos locais de trabalho, estando os inseticidas entre os agentes causadores de dermatites alérgicas de contato. Prüss-Üstün, Wolf, Corvalán, Bos, \& Neira, (2016), em publicação da Organização Mundial de Saúde, também relataram que algumas ocupações estão em maior risco de doenças de pele, como por exemplo, os trabalhadores que frequentemente manuseiam líquidos e substâncias químicas. Sharma et al. (2018) em pesquisa recente envolvendo dermatite de contato em trabalhadores agrícolas na Índia, também encontraram correlação entre as dermatites e a exposição a defensivos agrícolas utilizados em cultivos regionais.

Portanto, uma vez constatado que os defensivos agrícolas têm grande potencial de deposição no corpo humano durante o preparo e aplicação da calda, a adoção de medidas de controle que visem a neutralização do contato dos produtos com os trabalhadores é de fundamental importância para a preservação da saúde humana.

\section{Conclusão}

Todas as partes do corpo humano avaliadas podem ser atingidas por defensivos agrícolas, destacando-se os pés como os membros consideravelmente mais atingidos.

As gotas depositadas sobre os aplicadores são homogêneas e majoritariamente classificadas como "muito finas". Logo, aponta-se que as gotas menores são potencialmente mais susceptíveis à deriva e à deposição sobre o aplicador.

A aplicação de defensivos agrícolas, por meio da utilização de pulverizador costal manual, demanda a utilização de EPIs capazes de neutralizar a exposição à agentes químicos para todas as partes do corpo dos aplicadores, de forma a promover a adequada segurança ocupacional.

O vento é capaz de influenciar todos os parâmetros de deposição $(\overline{Q G}, \overline{D M V}, \overline{\operatorname{Span}}, \overline{A c})$ mas os pés permanecem sendo os membros consideravelmente mais atingidos.

Sob condições de vento, ocorre o aumento do diâmetro das gotas que incidem sobre os aplicadores e reduz-se a homogeneidade dessas. 
A incidência de vento também potencializa a deriva e consequente aumento da deposição de defensivos agrícolas sobre o aplicador.

Além da adequada manutenção dos pulverizadores costais, a utilização de EPIs impermeáveis nas possíveis partes atingidas pelos vazamentos e gotejamentos é extremamente necessária para a neutralização da exposição aos defensivos agrícolas.

Sugere-se como continuidade da presente pesquisa que trabalhos futuros investiguem a deposição de defensivos agrícolas sobre o aplicador/operador utilizando-se outros equipamentos e máquinas de pulverização, tais como: os atomizadores costais, os pulverizadores autopropelidos, as aeronaves e os VANTs (Veículos Aéreos Não Tripulados).

\section{Agradecimentos}

Os autores agradecem o apoio à pesquisa da Coordenação de Aperfeiçoamento de Pessoal de Nível Superior (CAPES) e ao Instituto Federal do Sudeste de Minas Gerais - Campus São João Del Rei.

\section{Referências}

Araújo, A. J. D., Lima, J. S. D., Moreira, J. C., Jacob, S. D. C., Soares, M. D. O., Monteiro, M. C. M., Amaral, A. M., Kubota, A., Meyer, A., Cosenza, C. A. N., Neves, C., \& Markowitz, S. (2007). Exposição múltipla a agrotóxicos e efeitos à saúde: estudo transversal em amostra de 102 trabalhadores rurais. Ciência \& Saúde Coletiva, 12, 115-130. doi.org/10.1590/S1413-81232007000100015

Baesso, M. M., Teixeira, M. M., Ruas, R. A. A., \& Baesso, R. C. E. (2014). Tecnologias de aplicação de agrotóxicos. Revista Ceres, 61, 780-785. doi.org/10.1590/0034-737X201461000003

Baio, F. H. R., Antuniasse, U. R., Castilho, B. R., Teodoro, P. E., \& Silva, E. E. (2019). Factors affecting aerial spray drift in the Brazilian Cerrado. Plos One, 14(2), 1-16. doi.org/10.1371/journal.pone.0217957

Baldi, I., Lebailly, P., Bouvier, G., Rondeau, V., Kientz-Bouchart, V., Canal-Raffin, M., \& Garrigou, A. (2014). Levels and determinants of pesticide exposure in re-entry workers in vineyards: Results of the PESTEXPO study. Environmental Research, 132, 360-369. doi.org/10.1016/j.envres.2014.04.035

Brasil. (1978). Ministério da economia. Norma Regulamentadora $n^{o} 9$ - Programa de Prevenção de Riscos Ambientais. Brasília, 1978. https://www.gov.br/trabalho-e-previdencia/pt-br/composicao/orgaos-especificos/secretaria-de-trabalho/inspecao/seguranca-e-saude-no-trabalho/normasregulamentadoras/nr-09-atualizada-2019.pdf

Jaga, K., \& Dharmani, C. (2003). Sources of exposure to and public health implications of organophosphate pesticides. Revista panamericana de salud pública, 14, 171-185. https://scielosp.org/article/rpsp/2003.v14n3/171-185/en/

Langenbach, T., Mano, D., Campos, M. M., Cunha, A. L. M. C., \& Campos, T. P. M. (2017). Pesticide dispersion by spraying under tropical conditions. Journal of Environmental Science and Health, 52(12), 843-849. doi.org/10.1080/03601234.2017.1359040

Linhart, C., Niedrist, G. H., Nagler, M., Nagrani, R., Temml, V., Bardelli, T., Wilhalm, T., Riedl, A., Zaller, J. G., Clausing, P., \& Hertoge, K. (2019). Pesticide contamination and associated risk factors at public playgrounds near intensively managed apple and wine orchards. Environmental Sciences Europe, 31(28), 1-16. doi.org/10.1186/s12302-019-0206-0

Londres, F. (2012). Agrotóxicos no Brasil: um guia para ação em defesa da vida. Rede Brasileira de Justiça Ambiental.

Marconi, M. A., Lakatos, E. M. (2017). Fundamentos da Metodologia Científica (8th ed.). São Paulo: Atlas.

Mewes, W. L. C., Teixeira, M. M., Fernandes, H. C., Zanuncio, J. C., \& Tiburcio, R. A. S. (2015). Parâmetros característicos da pulverização pneumática em copas de árvores de eucalipto. Revista Árvore, 39(4), 635-640. doi.org/10.1590/0100-67622015000400005

Minguela, J. V., \& Cunha, J. P. A. R. (2017). Manual de aplicação de produtos fitossanitários. Aprenda Fácil.

Moraes, M. V. G. (2010). Doenças ocupacionais-agentes: físicos, químicos, biológicos, ergonômicos (1st ed.). Érica.

Oliveira, P. S., Vitória, E. L., Crause, D. H., \& Campanharo, A. (2019). Espectro de gotas e uniformidade de distribuição de calda em cafeeiro conilon aplicada por pulverização pneumática. X Simpósio de Pesquisa dos Cafés do Brasil, Vitória-ES. http://www.consorciopesquisacafe.com.br/ojs/index.php/SimposioCafe2019/article/view/445/274

Pereira, L. N., \& Amorim, J. G. B. (2020). Condições de segurança do trabalho no manuseio de agrotóxicos em pequenas propriedades de agricultura familiar. Revista Ibero-Americana de Ciências Ambientais, 11(7), 349-364. doi.org/10.6008/CBPC2179-6858.2020.007.0029

Peres, F., Oliveira-Silva, J. J., Della-Rosa, H. V., \& Lucca, S. R. d. (2005). Challenges in the study of human and environmental contamination by pesticides. Ciência \& Saúde Coletiva, 10, 27-37. doi.org/10.1590/S1413-81232005000500006 
Research, Society and Development, v. 11, n. 1, e24311124889, 2022

(CC BY 4.0) | ISSN 2525-3409 | DOI: http://dx.doi.org/10.33448/rsd-v11i1.24889

Picanço, M. V., Morais, E. G. F., Silva , G. A., Souza Júnior, R. C., Chediak , M., \& Moreira, M. D. (2014). Controle químico de pragas (4th ed.). Os editores.

Prüss-Üstün, A., Wolf, J., Corvalán, C. F., Bos, R., \& Neira, M. (2016). Preventing disease through healthy environments: a global assessment of the burden of disease from environmental risks. World Health Organization.

Sharma, A., Mahajan, V. K., Mehta, K. S., Chauhan, P. S., Sharma, V., Sharma, A., Wadhwa, D., \& Chauhan, S. (2018). Pesticide contact dermatitis in agricultural workers of Himachal Pradesh (India). Contact dermatitis, 79(4), 213-217. doi.org/10.1111/cod.13049

Shengde, C., Lan, Y., Jiyu, L., Zhiyan, Z., Aimin, L., \& Yuedong, M. (2017). Effect of wind field below unmanned helicopter on droplet deposition distribution of aerial spraying. International Journal of Agricultural and Biological Engineering, 10(3), 67-77. doi.org/10.3965/j.ijabe.20171003.3078

Spadotto, C. A. (2006). Influência das condições meteorológicas no transporte de agrotóxicos no ambiente. Boletim SBMET, 30(1), 15-20. http://www.alice.cnptia.embrapa.br/alice/handle/doc/15393

Vitória, E. L. D., \& Campanharo, A. (2016). Amostra de etiquetas de papel hidrossensíveis para determinação de espectro de gotas em pulverização no cafeeiro canephora. Coffe Science, Lavras-MG. http://www.sbicafe.ufv.br/handle/123456789/8032

Wang, J., Lan, Y., Zhang, H., Zhang, Y., Wen, S., Yao, W., \& Deng, J. (2018). Drift and deposition of pesticide applied by UAV on pineapple plants under different meteorological conditions. International Journal of Agricultural and Biological Engineering, 11(6), 5-12. doi.org/10.25165/j.ijabe.20181106.4038

Wilhelm, C. M., Calsing, A. K., \& Silva, L. B. (2015). Assessment of DNA damage in floriculturists in southern Brazil. Environmental Science and Pollution Research, 22, 8182-8189. doi.org/10.1007/s11356-014-3959-4 